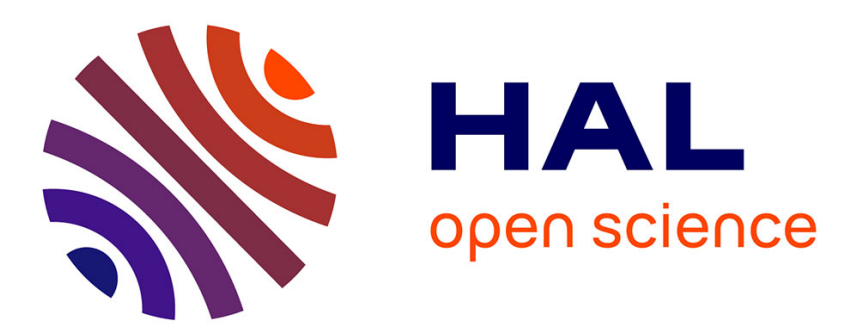

\title{
Comparison between approaches for the experimental determination of metastable zone width: A case study of the batch cooling crystallization of ammonium oxalate in water
}

Nesrine Gherras, Gilles Févotte

\section{To cite this version:}

Nesrine Gherras, Gilles Févotte. Comparison between approaches for the experimental determination of metastable zone width: A case study of the batch cooling crystallization of ammonium oxalate in water. Journal of Crystal Growth, 2012, 342 (1), pp.88-98. 10.1016/j.jcrysgro.2011.05.028 . hal00680268

\section{HAL Id: hal-00680268 \\ https://hal.science/hal-00680268}

Submitted on 17 Sep 2012

HAL is a multi-disciplinary open access archive for the deposit and dissemination of scientific research documents, whether they are published or not. The documents may come from teaching and research institutions in France or abroad, or from public or private research centers.
L'archive ouverte pluridisciplinaire HAL, est destinée au dépôt et à la diffusion de documents scientifiques de niveau recherche, publiés ou non, émanant des établissements d'enseignement et de recherche français ou étrangers, des laboratoires publics ou privés. 


\title{
Comparison between approaches for the experimental determination of metastable zone width: a case study of the batch cooling crystallization of ammonium oxalate in water
}

\author{
GHERRAS Nesrine ${ }^{\mathrm{a}}$, FEVOTTE Gilles, ${ }^{\mathrm{a}, \mathrm{b} *}$ \\ ${ }^{a}$ Ecole des Mines de Saint Etienne, centre SPIN, LPMG, UMR CNRS 5148. \\ 158, cours Fauriel. 42000 Saint Etienne (France) \\ ${ }^{\mathrm{b}}$ Université de Lyon, Université Lyon 1, 43 bld du 11 Novembre 1918. 69100 Villeurbanne (France)
}

\begin{abstract}
In situ ATR-FTIR spectroscopy coupled with in situ image acquisition measurements were used to determine the solubility curve and to investigate the metastable zone width (MSZW) of ammonium oxalate monohydrate (AO) aqueous solutions under polythermal conditions. The experimental data allowed estimating the MSZW and induction time of the system and the results were compared with published literature values for the same system (Sangwal, 2009). "Pseudo" induction time estimation techniques based on polythermal methods showed that AO aqueous solutions exhibit two nucleation regimes depending on the cooling rates.

Even though they are based on rough and questionable assumptions, induction time and MSZW estimation methods are often considered as essential for the development of industrial crystallization processes. However, both the relevancy and the physical meaning of the results provided by these methods is uncertain. In the actual industrial context where many advanced measurement techniques and modeling tools became available, the present paper intends to call into question the outcome of the notions of MSZW and induction time.
\end{abstract}

Keywords: A1. Nucleation, A1. Industrial crystallization, A1. Metastable zone, A1. Induction time, B3. Sensors

\footnotetext{
*Corresponding authors: gherras@emse.fr; fevotte@emse.fr;
} 


\section{Introduction}

Present in all heterogeneous transformations, nucleation has an essential and specific character in the field of industrial crystallization. It is the "first" process which determines the overall number of crystals during a given operation and consequently the evolution and final properties of the obtained solid particles, in the first rank of which the size.

Aiming at obtaining partial information on the nucleation kinetics, many different methods have been reported in the literature [1-8]. The formation of a new solid phase can be detected in several different ways, for example, through the appearance of crystals or through changes of the solution properties (turbidity, refractive index) [9-11]. The method used for detecting the onset of nucleation has an influence on the result of the kinetic estimation, in particular because the time required for the critical nucleus to grow to a detectable size [12] depends on the technique used.

In the present work, ATR-FTIR spectroscopy and in situ image analysis were used to determine solubility curves and to help characterize the nucleation properties of the material. As an extension of an earlier work [1] devoted to the crystallization of Ammonium Oxalate (AO), the effect of cooling rates on the MSZW is studied and nucleation parameters are calculated using different approaches and compared to those obtained by Sangwal [1].

The goal of the comparison is to put into question the "historical" methods mentioned above which are all based on rough assumptions. This work is also aimed at preparing the report of a more in-depth study [13] of nucleation phenomena observed during the batch cooling crystallization of Ammonium Oxalate (AO) monohydrate in water. The major objective of the overall study (i.e. the present paper and [13]) is to suggest that thanks to the use of PATs (Process Analytical Technologies) and Population Balance Equation (Referred to as PBE in the following) modeling, time has come for a wider industrial use of advanced methods allowing to determine the many possible nucleation mechanisms occurring during industrial crystallization and to estimate the "true" related kinetics. 


\section{Theoretical approaches of metastable zone width and induction time measurements}

According to the nucleation theories, the nucleation rate $\mathrm{J}$ depends on the relative supersaturation $\mathrm{S}$, and there is a threshold value of relative supersaturation $\mathrm{S}_{\max }$ beyond which the metastable phase precipitates spontaneously into the new stable phase, The MSZW qualifies this supersaturation domain.

Overviews of published MSZW correlations are available in the literature [14-16]. In a recent series of papers, Kobari, Kubota et al. [17] proposed a unified approach of the many methods and experimental data related to the notions of MSZW and induction time [8, 17, 18]. Experimental and simulation results were systematically analyzed; it was shown that the different approaches reported in the literature are consistent and allow understanding features of the nucleation process. However, it remains undeniable that many physical aspects of nucleation are not rigorously taken into account by the methods in question. It is clear for example that the role played by crystal growth during the time spent before the end of the so-called induction period should explicitly be taken into account (which is not the case). The usual implicit notion of steady-state nucleation rate is also questionable because, as supersaturation changes (even during a limited time period) the total number of nucleï cannot be clearly defined. This is obviously true for methods based on constant cooling rates but also for constant supercooling induction time measurements. Another important example of the lack of physical rigor of the definition of the induction time is the meaning of the "detectable amount" of nucleated particles. The latter is known to depend on the "sensitivity" of the technique used to monitor the crystallization process during its very preliminary steps: measuring unambiguously the initial number density of primary and secondary nuclei is not possible today.

Two main techniques are currently used for determining the metastable zone width, the polythermal technique [19] which is perhaps most widely used, and the isothermal method also 
called induction time method. Supersaturation can also be generated applying constant cooling rate, as proposed by Kim and Mersmann [15], and explained in more details below.

The first method refers to Nývlt's equation involving two parameters (the "apparent nucleation order", $\mathrm{m}$ and the "mass nucleation rate constant", $\mathrm{k}$ ), which have no real physical meaning. Nývlt's equation has been extensively used in the past for the analysis of experimental data on nucleation kinetics.

More recently, Sangwal and coworkers $[1,20]$ proposed two approaches for explaining the dependence of the MSZW on various factors. The first of these latter approaches is based on the classical three dimensional nucleation theory while the second method is based on power-law relationship between the nucleation rate and the maximum supersaturation, $S_{\max }$.

\subsection{Nývlt's approach}

Using the classical nucleation theory (CNT) and assuming that the nucleation rate at the onset of primary nucleation corresponds to some constant "steady-state" supersaturation for a limited time period (i.e. the variations $\mathrm{d}(\Delta \mathrm{C}) / \mathrm{dt}$ and $\mathrm{dC} * / \mathrm{dt}$ are assumed to be equal), the primary

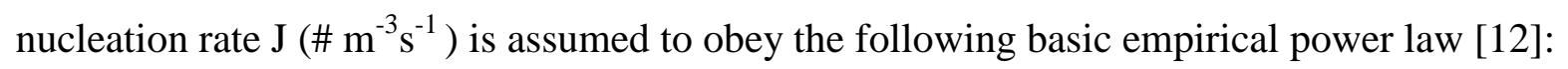

$$
\mathrm{J}=\mathrm{k}\left(\Delta \mathrm{C}_{\max }\right)^{\mathrm{m}}
$$

Where $\mathrm{k}$ is the mass nucleation rate constant $\left(\mathrm{kg}^{-\mathrm{m}} \mathrm{m}^{3 \mathrm{~m}-3} \mathrm{~s}^{-1}\right)$, $\mathrm{m}$ is the apparent nucleation order and $\Delta \mathrm{C}_{\max }$ is the absolute supersaturation $\left(\mathrm{kg} \mathrm{m}^{-3}\right)$. In the following, the nucleation temperature is denoted as $\mathrm{T}_{\max }$ and $\mathrm{T}_{0}$ refers to the solubilization temperature, $\Delta \mathrm{T}_{\max }$ is therefore the difference between $\mathrm{T}_{0}$ and $\mathrm{T}_{\max }$.

From Eq.(1), Nývlt expresses the MSZW in terms of $\Delta \mathrm{T}_{\max }$ as a function of the linear cooling rate $\mathrm{R}=-\mathrm{dT} / \mathrm{dt}$ for a given saturation temperature. The following expression can be demonstrated, where $\mathrm{dC} * / \mathrm{dT}$ is the slope of the solubility curve:

$$
\ln \Delta \mathrm{T}_{\max }=\left[\left(\frac{1}{\mathrm{~m}}-1\right) \ln \left(\frac{\mathrm{dC^{* }}}{\mathrm{dT}}\right)-\frac{1}{\mathrm{~m}} \ln \mathrm{k}\right]+\left(\frac{1}{\mathrm{~m}}\right) \ln \mathrm{R}
$$


The plot of $\ln (\mathrm{R})$ vs. $\ln (\Delta \mathrm{Tmax})$ is expected to give a straight line, with the slope yielding the apparent nucleation order $\mathrm{m}$. The mass nucleation rate constant, $\mathrm{k}$, is estimated from the intercept. The number nucleation rate constant can be calculated using Eq. (3) as follows:

$$
\frac{\mathrm{dN}}{\mathrm{dt}}=\mathrm{k}(\Delta \mathrm{C})^{\mathrm{m}}=\mathrm{k}^{\prime} \alpha \rho \mathrm{r}^{3}(\Delta \mathrm{C})^{\mathrm{m}}
$$

Where $\mathrm{N}$ is the number of formed nuclei and $\mathrm{k}$ is the mass nucleation rate constant, $\mathrm{k}$ ' the number nucleation constant, $\alpha$ the volumetric shape factor, $\rho$ the mass-based crystal density and $r$ is the size of detectable nuclei at the maximum supersaturation, which is usually assumed to be $10 \mu \mathrm{m}[10,21]$.

\subsection{Sangwal's interpretation of MSZW}

\subsubsection{Self-consistent Nývlt- like equation}

Sangwal [1] simplified the complicated units of Nývlt's Nucleation constant k, by expressing the nucleation rate $\mathrm{J}\left(\# \mathrm{~m}^{-3} \mathrm{~s}^{-1}\right)$ using the following power-law relationship:

$$
\mathrm{J}=\mathrm{K}\left(\ln \mathrm{S}_{\max }\right)^{\mathrm{m}}
$$

where, $\mathrm{K}$ is a new nucleation constant $\left(\# \mathrm{~m}^{-3} \mathrm{~s}^{-1}\right), \mathrm{m}$ the apparent nucleation order and $\mathrm{S}$, as above, is the relative supersaturation.

Using the theory of regular solutions to express $\ln \mathrm{S}_{\max }$, and approximating the primary nucleation rate $\mathbf{J}$ as a function of the time variations of $S$, Sangwal obtained a relationship between the dimensionless maximum temperature $\Delta \mathrm{T}_{\max } / \mathrm{T}_{\mathrm{O}}$ and the cooling rate $\mathrm{R}$ :

$$
\ln \left(\frac{\Delta \mathrm{T}_{\max }}{\mathrm{T}_{0}}\right)=\varphi^{\prime}-\beta \ln \mathrm{T}_{0}+\beta \ln \mathrm{R}=\varphi+\beta \ln \mathrm{R}
$$

where $\varphi^{\prime}-\beta \ln \mathrm{T}_{0}=\varphi ; \quad \beta=1 / \mathrm{m} \beta=1 / m$ and $\varphi^{\prime}=\frac{1-\mathrm{m}}{\mathrm{m}} \ln \left(\frac{\Delta \mathrm{H}_{\mathrm{s}}}{\mathrm{R}_{\mathrm{g}} \mathrm{T}_{\max }}\right)+\frac{1}{\mathrm{~m}} \ln \frac{\mathrm{f}}{\mathrm{K}}$, 
$\Delta \mathrm{H}_{\mathrm{s}}$ is the heat of dissolution, $\mathrm{R}_{\mathrm{g}}$ is the perfect gas constant and $\mathrm{f}$ is a constant expressed in number nuclei $/ \mathrm{m}^{3}$.

As Eq. (2), Eq. (5) therefore predicts a linear relationship between $\ln \Delta \mathrm{T}_{\max } / \mathrm{T}_{0}$ and $\ln \mathrm{R}$.

\subsubsection{Classical three-dimensional nucleation theory approach (3D-CNT)}

The lack of clear physical meaning for both parameters $\mathrm{K}$ and $\mathrm{m}$, led Sangwal to propose the other following approach. According to the classical nucleation theory, the nucleation rate $\mathrm{J}$ (in $\# . \mathrm{m}^{-3} \mathrm{~s}^{-1}$ ) is given by the following equation [21]:

$$
\begin{aligned}
& J=A \exp \left[\frac{-B}{\left(\operatorname{LnS}_{\max }\right)^{2}}\right] \\
& B=\frac{16 \pi}{3}\left(\frac{\gamma \Omega^{2 / 3}}{T_{\text {max }} \mathrm{K}_{\mathrm{B}}}\right)^{3}
\end{aligned}
$$

Where, A is a kinetic constant $\left(\# \mathrm{~m}^{-3} \mathrm{~s}^{-1}\right), \gamma$ is the solid-liquid interface energy, $\Omega$ is the molecular volume and $K_{B}$, the Boltzmann constant.

Using the same set of equations as above, Sangwal derived a new expression relating the maximum supercooling and saturation temperature to the linear cooling rate R:

$$
\left(\frac{\mathrm{T}_{0}}{\Delta \mathrm{T}_{\max }}\right)^{2}=\mathrm{F}_{1}\left[-\ln \mathrm{R}+\mathrm{X}+\ln \mathrm{T}_{0}\right]=\mathrm{F}-\mathrm{F}_{1} \ln \mathrm{R}
$$

Where, $\quad F=F_{1}\left(X+\ln T_{0}\right), F_{1}=\frac{1}{B}\left(\frac{\Delta H_{S}}{R_{g} T_{\max }}\right)$ and $X=\ln \left(\frac{A}{f} \frac{R_{g} T_{\max }}{\Delta H_{s}}\right)$.

Eq. (8) predicts that $\left(\frac{\mathrm{T}_{0}}{\Delta \mathrm{T}_{\max }}\right)^{2}$ decreases linearly when $\ln \mathrm{R}$ increases. $\mathrm{F}$ and $\mathrm{X}$ are related to $\mathrm{B}$ (thermodynamic constant) and A (kinetic constant) defined by the 3D CNT (Three-Dimensionnal Classical Nucleation Theory). 


\subsection{Kubota's interpretation}

\subsubsection{Metastable zone width}

Kubota suggested another approach to account for the dependence of the MSZW on the detection technique for a given system. The MSZW is assumed to correspond to the point at which the number density of grown nuclei reaches a fixed, but unknown value [8]. The primary nucleation rate in number basis $\mathbf{J}$ is approximated by the following expression:

$$
\mathrm{J}=\mathrm{k}_{\mathrm{n}}(\Delta \mathrm{T})^{\mathrm{n}}
$$

The number density $\mathrm{N}_{\mathrm{m}} / \mathrm{V}$ of accumulated crystals (grown primary nuclei), during the time $t_{\mathrm{m}}$ can simply be obtained by integrating the nucleation rate as:

$$
\frac{N_{m}}{V}=\int_{0}^{N_{m}} d\left(\frac{N}{V}\right)=\int_{0}^{t_{m}} J d t
$$

Where $N_{m}$ is the accumulated number $N$ of grown primary nuclei during the time $t_{\mathrm{m}}$ and $V$ is the working volume of the crystallizer. Assuming a constant cooling rate and constant $k_{n}$ in the considered temperature range, Eq. (10) is converted to the following equation:

$$
\log \left(\Delta \mathrm{T}_{\mathrm{m}}\right)=\frac{1}{\mathrm{n}+1} \log \left[\left(\frac{\mathrm{N}_{\mathrm{m}}}{\mathrm{Vk}_{\mathrm{n}}}\right)(1+\mathrm{n})\right]+\left(\frac{1}{1+\mathrm{n}}\right) \log \mathrm{R}
$$

Where $\Delta T_{\mathrm{m}}$ is the MSZW at which the number density of accumulated crystals $N_{\mathrm{m}} / V$ reaches a fixed value. This expression is similar to that of Nývlt, but the nucleation constant $k_{n}$ cannot be determined as the actual value of $N_{\mathrm{m}} / V$ depends on the detection technique and requires additional experiments to be measured. According to Mersmann [21-22], when turbidimetry is used, the detectable number density at the point where nucleation is observed in solutions is about $10^{11} \mathrm{\#} / \mathrm{m}^{3}$ for particles with an average size of $10 \mu \mathrm{m}$.

\subsubsection{Induction time measurements}

Nỳvlt's theory does not give any insight into the induction time while, using the assumptions presented above, Kubota expresses the induction time $t_{\text {ind }}$ in the following equation: 


$$
\mathrm{t}_{\text {ind }}=\left(\frac{\mathrm{N}_{\mathrm{m}}}{\mathrm{Vk}_{\mathrm{n}}}\right) \Delta \mathrm{T}^{-\mathrm{n}}
$$

\subsection{D-CNT approach for "pseudo" induction time measurements:}

The so-called "pseudo" induction time measurement method is based on the observation of nucleation during cooling experiments (i.e., pseudo refers here to non isothermal operation). The solution is first driven in the supersaturated zone until a given constant temperature $\mathrm{T}_{\mathrm{i}}\left(50^{\circ} \mathrm{C}\right.$ in the following) where it is supposed to reach a steady-state. After stabilization, the solution is cooled at constant cooling rate, until nucleation is observed. The induction period of nucleation $\mathrm{t}_{\text {ind }}$ is here defined as the time elapsed between the moment when the supersaturated state is reached in the old phase and the moment at which an appreciable amount of new solid phase particles is produced [4]. If supersaturation is formed at a constant cooling rate until the first crystals are detected, the relationship between the metastable zone width $\Delta \mathrm{T}_{\max }$ and the induction time $\mathrm{t}_{\text {ind }}$ is the following $\left(50^{\circ} \mathrm{C}\right)$ :

$$
\mathrm{t}_{\text {ind }}=1 / \mathrm{JV}=\left(\mathrm{T}_{\mathrm{i}}-\mathrm{T}_{\max }\right) / \mathrm{R}
$$

where $T_{i}$ is the initial stabilization temperature $\left(50^{\circ} \mathrm{C}\right)$; V is the solution volume, $\mathrm{J}$ is the nucleation rate.

Using Eqs. (5), (6), (12) and rearranging, the induction period is now given by the following

equation according to which a plot of $\ln \mathrm{t}_{\text {ind, }}$, against $\left[(\ln S \max )^{2} \mathrm{~T}_{\max }^{3}\right]^{-1}$ yields a straight line:

$$
\ln \left(\frac{\Delta \mathrm{T}_{\max }}{\mathrm{R}}\right)=\ln \mathrm{t}_{\text {ind }}=\ln \left(\frac{1}{\mathrm{AV}}\right)+\left[\frac{16 \pi \gamma^{3} \Omega^{2}}{3 \mathrm{~K}_{\mathrm{g}}^{3}(\ln \mathrm{S} \max )^{2} \mathrm{~T}_{\max }^{3}}\right]
$$

\section{Experimental design.}

\subsection{Materials}

Ammonium Oxalate monohydrate (AO) was used is this study without further purification. The powder was available from Acros Organics with a purity level of 99+\%. 


\subsection{Batch crystallizer set up and characterization techniques}

As displayed in Fig.1, a 3 L glass vessel equipped with a jacket and a condenser was used for the experiments. Stainless-steel baffles and a high efficiency propeller (Mixel $\mathrm{TT}^{\mathrm{TM}}$ ) are used to maintain a good homogeneity of particles in the slurry. The whole operating device is instrumented and computer controlled to allow the monitoring of setpoint temperature trajectories. Cooling is ensured by means of heat transfer through the jacket wall. The temperature in the reactor is thus controlled by manipulating the set-point temperature of a $2 \mathrm{~kW}$ heating bath containing water with an accuracy of $\pm 0,05^{\circ} \mathrm{C}$.

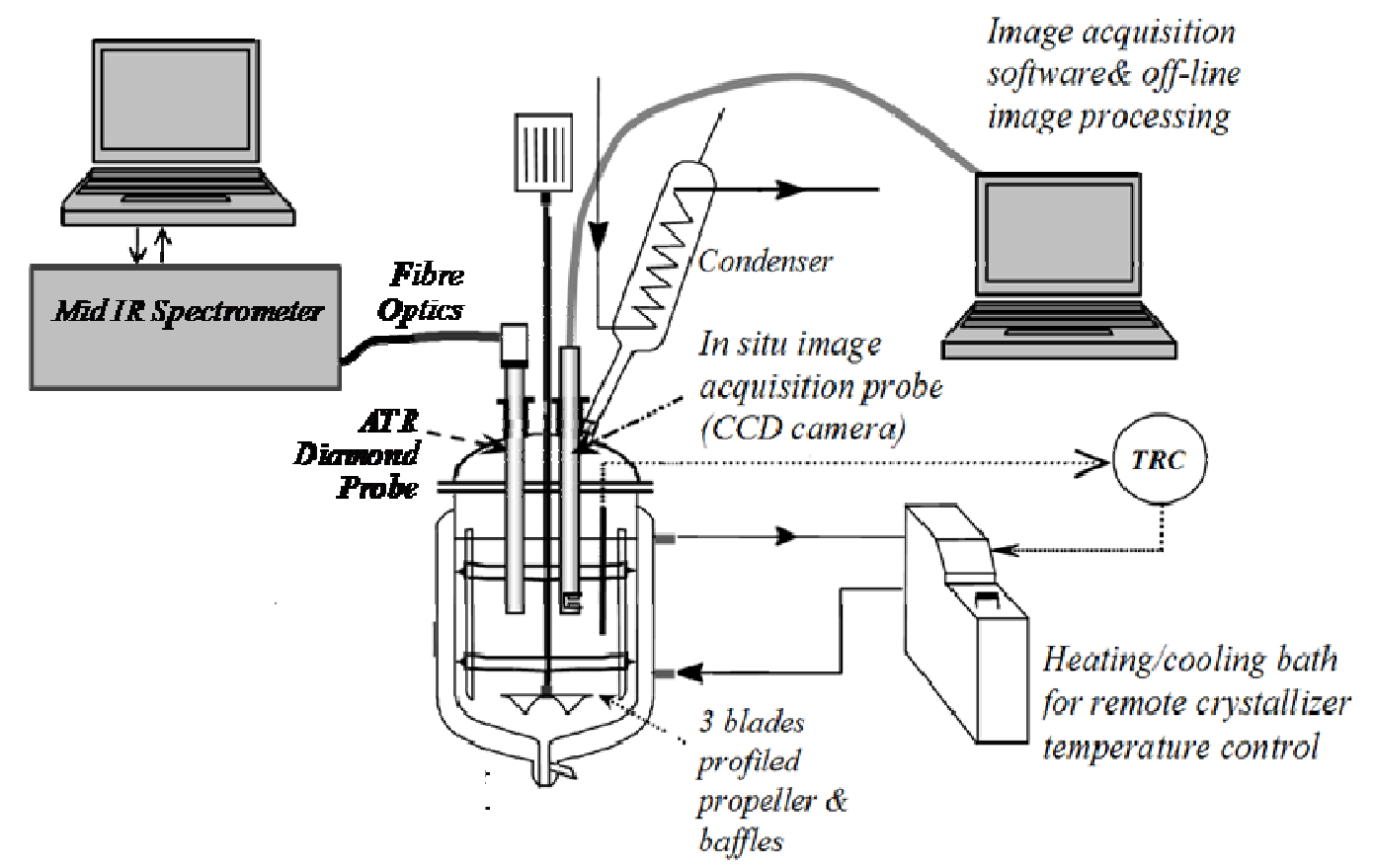

Figure 1: Experimental set up: temperature controlled and well-mixed batch crystallizer equipped with ATR-FTIR and in situ image acquisition probes.

\subsubsection{Liquid phase monitoring}

In situ solute concentration measurements were performed using the FTIR spectrometer "MATRIX-F" manufactured by Brucker Optik GmbH, equipped with an ATR-diamond immersion probe (diamond prism with two reflexion angles of $45^{\circ}$ ). As shown in Fig.1, the ATR 
probe is connected to the spectrometer through optical fiber. The measurement cell, the optical conduit and the probe were purged with nitrogen to reduce the sensitivity of the measurements to the time variations of the concentration of water and carbon dioxide in the ambient air. Detection was ensured by a MCT detector cooled with liquid nitrogen (endurance 12 hours).

Preliminary solution cooling crystallizations of AO were carried out to assess the time variations of the recorded IR spectra during batch operations. Due to the effect of temperature variations during cooling and to the high absorption of solvent (water) in the mid IR spectrum, air was selected as a reference to compute the relative absorbances.

\subsubsection{Solid phase monitoring}

In addition to the ATR- FTIR measurement of supersaturation, the appearance of the new solid phase was monitored using «EZProbe», an imaging probe developed at the University of Lyon. Typical pictures obtained by means of the CCD camera inserted in the "EZProbe" during crystallization processes are presented elsewhere and more details about the probe technical characteristics and developed algorithm used for image processing can be found in reference [23]. Fig. 2 , shows the first detectable particles during AO batch cooling crystallization. The first image in Fig (2a) represents the very first detection of one single moving particle in the fixed background. In the following inserts, circles indicate other early detected crystals with sizes ranging from 7 to $15 \mu \mathrm{m}$. 

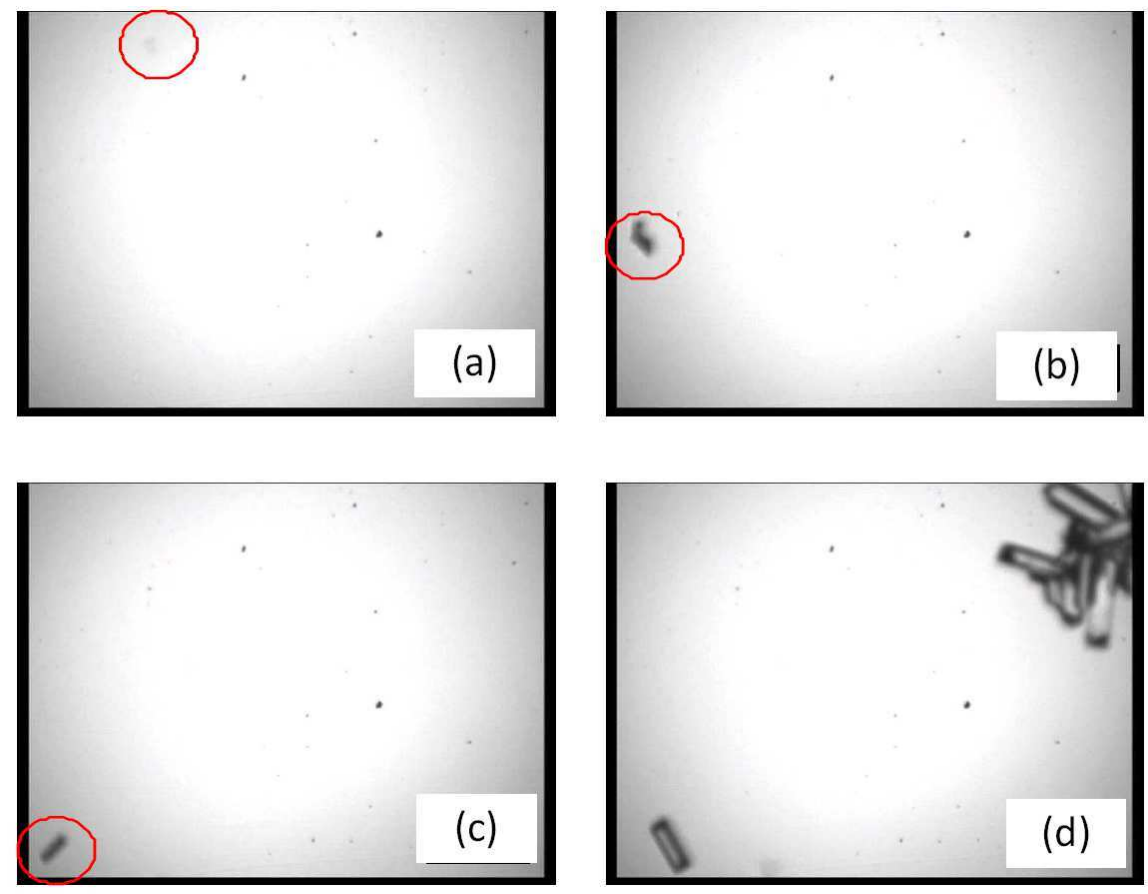

Figure 2: 2D images obtained using the in situ imaging probe: acquisition of the very first observable crystals in the crystallizer after the onset of nucleation.

\subsection{Experimental procedures}

\subsubsection{ATR-FTIR calibration measurements}

The temperature and concentration ranges used in the calibration experiments were dictated by the solubility of Ammonium Oxalate monohydrate (AO). Calibration samples were prepared through dissolution of $\mathrm{AO}$ monohydrate powder in distilled water so as to cover the concentration range between 0 and $0.16 \mathrm{~kg} \mathrm{AO} / \mathrm{kg}$ water. The samples were heated and stirred until a homogeneous undersaturated solution was obtained in the crystallizer. Complete dissolution was assumed to be achieved when the infrared signal remained constant during a period of 2 hours at a fixed temperature. The IR spectra were then collected in order to compute a calibration model required to establish a relationship between the dissolved solute concentration and measured spectral features. The reference spectra were collected every $60 \mathrm{~s}$ during 1 hour and averaged. Additional spectra were also acquired for validation purposes. In order to cover the whole range of process conditions, the procedure was performed at different concentrations ranging from 0 to $0.16 \mathrm{~kg} / \mathrm{kg}$ solution by raising stages of $0.01 \mathrm{~kg} / \mathrm{kg}$ and three 
temperatures were set for each concentration (solubility temperature $\pm 2{ }^{\circ} \mathrm{C}$ ). The temperature range covered by the experiments varied between 10 and $65^{\circ} \mathrm{C}$. Many spectra (32 scans/spectrum) were thus acquired with a resolution of $4 \mathrm{~cm}^{-1}$ for each experimental condition. The collected spectra were then preprocessed $\left(\mathrm{CO}_{2}\right.$ and $\mathrm{H}_{2} \mathrm{O}$ bands correction and vectorial normalization of the spectra) and the values of absorbance were used to establish a calibration relationship allowing the computation of the dissolved solid concentrations. The latter calibration was designed using multivariable chemometrics model based on Partial Least Square (PLS) technique.

The calibration model was finally found to provide a measurement of the dissolved solid concentration with a relative uncertainty of the order of $0.3 \%$ in the investigated concentration and temperature ranges. More details about ATR FTIR calibration and supersaturation measurements can be found elsewere [24-26].

\subsubsection{Solubility measurements}

Once a suitable calibration model was validated, the solubility of AO in water was measured using in situ ATR-FTIR spectroscopy. Two different methods were then applied.

Method 1: based on solubility data published by Söhnel and Novotny [27] AO was dissolved in $1.8 \mathrm{~L}$ of bi-distillated water to obtain a concentration of $0.133 \mathrm{~kg} / \mathrm{kg}$ solution. This solution was kept at a constant temperature of $59^{\circ} \mathrm{C}$ during 2 hours to ascertain its complete dissolution. Then, the undersaturated solution was cooled from the dissolution temperature to $10^{\circ} \mathrm{C}$, at a slow cooling rate $\mathrm{R}=-\mathrm{dT} / \mathrm{dt}=2^{\circ} \mathrm{C} / \mathrm{h}$. ATR FTIR spectra were collected every $60 \mathrm{~s}$.

Method 2: a suspension saturated with an excess of AO solid material $(0.16 \mathrm{~kg} / \mathrm{kg}$ solution) was heated from 10 to $60^{\circ} \mathrm{C}$ at a rate of $2^{\circ} \mathrm{C} / \mathrm{h}$, thereby slowly dissolving the $\mathrm{AO}$. The same solution was also cooled with $\mathrm{R}=2^{\circ} \mathrm{C} / \mathrm{h}$ from $60^{\circ} \mathrm{C}$ to $10^{\circ} \mathrm{C}$, thereby slowly crystallizing the AO. Due to the slow heating/cooling procedure, the suspension was assumed to be at equilibrium, i.e. the liquid phase was always at its saturation concentration (which was experimentally checked $a$ 
posteriori). At $10,20,30,40,50$ and $60^{\circ} \mathrm{C}$, the temperature was held constant for 3 hours to make sure that equilibrium conditions were maintained during the entire course of experiment. Using the calibration model described above, the ATR-FTIR spectra were then used to obtain solubility values. The obtained solubility curve is displayed in Fig.3 which also reports some literature data [28-29]. It can be noticed that the results obtained by IR spectroscopy show a very good agreement with published data (the average relative difference between ATR measurements and literature data is about $0.12 \%)$. The solubility curve $\mathrm{C}^{*}(\mathrm{~T})$ was fitted with the following polynomial equation (95\% confidence for parameters fit, $\mathrm{T}$ in ${ }^{\circ} \mathrm{C}$ and $\mathrm{C}^{*}$ in $\mathrm{kg} / \mathrm{kg}$ solution):

$$
C^{*}(\mathrm{~T})=2.2710^{-5}\left( \pm 6.710^{-8}\right) \mathrm{T}^{2}+5.3910^{-4}\left(\left( \pm 5.610^{-6}\right) \mathrm{T}+2.8710^{-2}\left( \pm 4.810^{-3}\right)\right.
$$

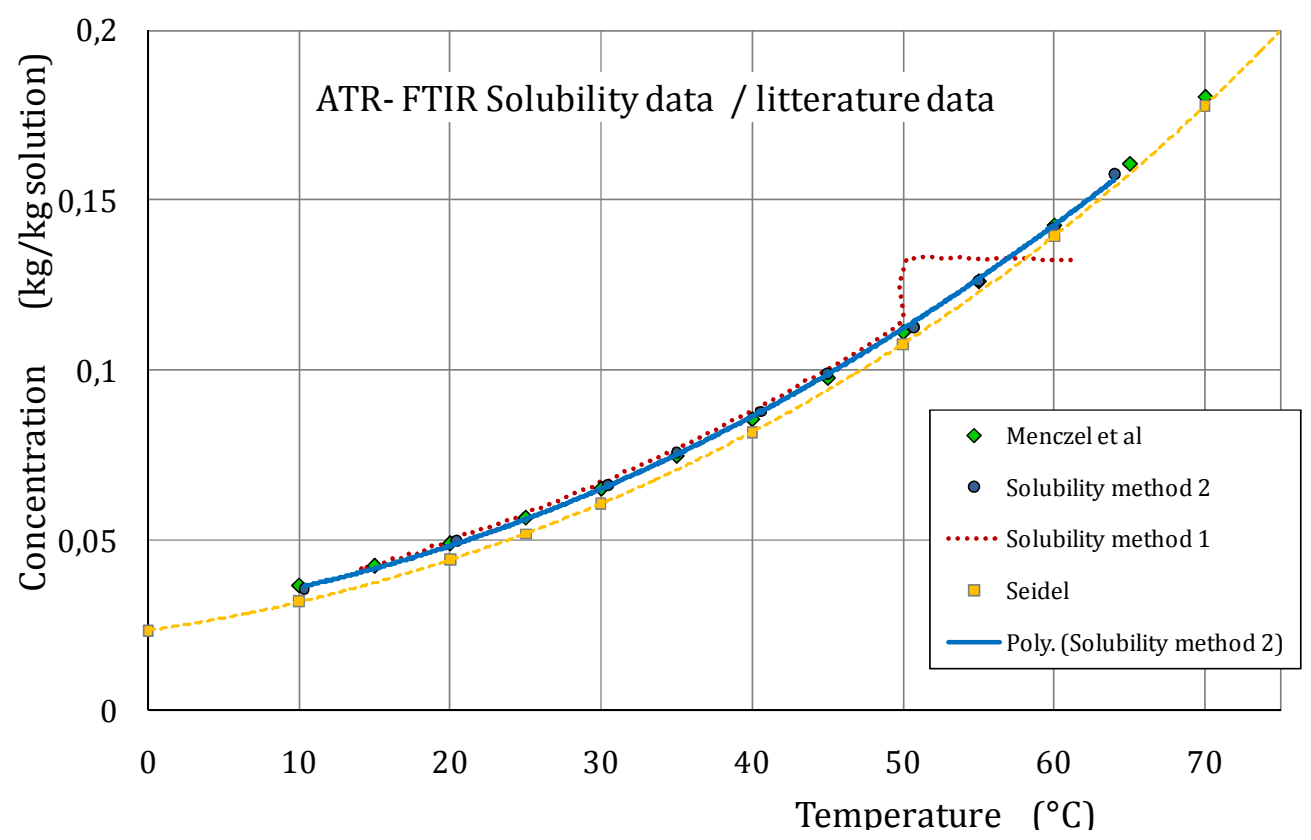

Figure 3: ATR-FTIR Measurements of the solubility curve of Amonium Oxalate using methods 1 and 2, and comparison with literature data (Seidel [28] and Menzel et al., [29]).

Supersaturation was computed in the following from the solute concentration measured using ATR FTIR and the solubility determined from both methods 1 and 2, assuming that the ratio between the related activity coefficients are close to one.

\subsubsection{Linear cooling experiments}

Ammonium Oxalate $(\mathrm{AO})$ undersaturated solutions were prepared by dissolving analytical grade 
monohydrate in $1.8 \mathrm{~L}$ distillated, de-ionized and degassed water, heated several $\mathrm{K}$ higher than the saturation temperature $\left(50^{\circ} \mathrm{C}\right)$ and maintained 2 hours at this temperature so as to reach a concentration of $0.1 \mathrm{~kg} / \mathrm{kg}$ solution. When both the ATR-FTIR spectrometer and the EZ-probe indicated complete dissolution, linear unseeded cooling experiments were carried out at different linear cooling rates, namely: $\mathrm{R}=5,7,10,12,20,25$ and $30^{\circ} \mathrm{C} / \mathrm{h}$. For each cooling rate, a set of at least 3 experiments was carried out to verify the repeatability of the process. All experiments were stopped at $20^{\circ} \mathrm{C}$ and left for isothermal stabilization during 3 hours.

Sangwal [1] investigated cooling rates ranging from $9.6{ }^{\circ} \mathrm{C} / \mathrm{h}$ to $57.6{ }^{\circ} \mathrm{C} / \mathrm{h}$. The temperature at which first nuclei were observed with the naked eye was taken as the limiting temperature $\mathrm{T}_{\text {lim. }}$. The maximum supercooling was calculated from saturation and limiting temperatures.

In the present study, the cooling rates used to investigate the MSZW ranged from $5^{\circ} \mathrm{C} / \mathrm{h}$ to $30^{\circ} \mathrm{C} / \mathrm{h}$. For the induction time approach, an additional rate of $2^{\circ} \mathrm{C} / \mathrm{h}$ was also investigated.

\section{Results and discussion}

\subsection{Concentration and supersaturation profiles}

The concentration and supersaturation profiles in Fig.4(a) \& (b) are similar for the three experiments carried at a cooling rate of $30^{\circ} \mathrm{C} / \mathrm{h}$ and $5^{\circ} \mathrm{C} / \mathrm{h}$. Before nucleation the concentration remains constant in all cases which indicates that the effect of temperature on the spectroscopic measurements is correctly taken into account. As expected, increasing cooling rates lead to increased maximal supersaturation values. $T_{\max }$ and $S_{\max }$ were determined using the first derivative of the relative supersaturation curve $\beta(\mathrm{t})$. 

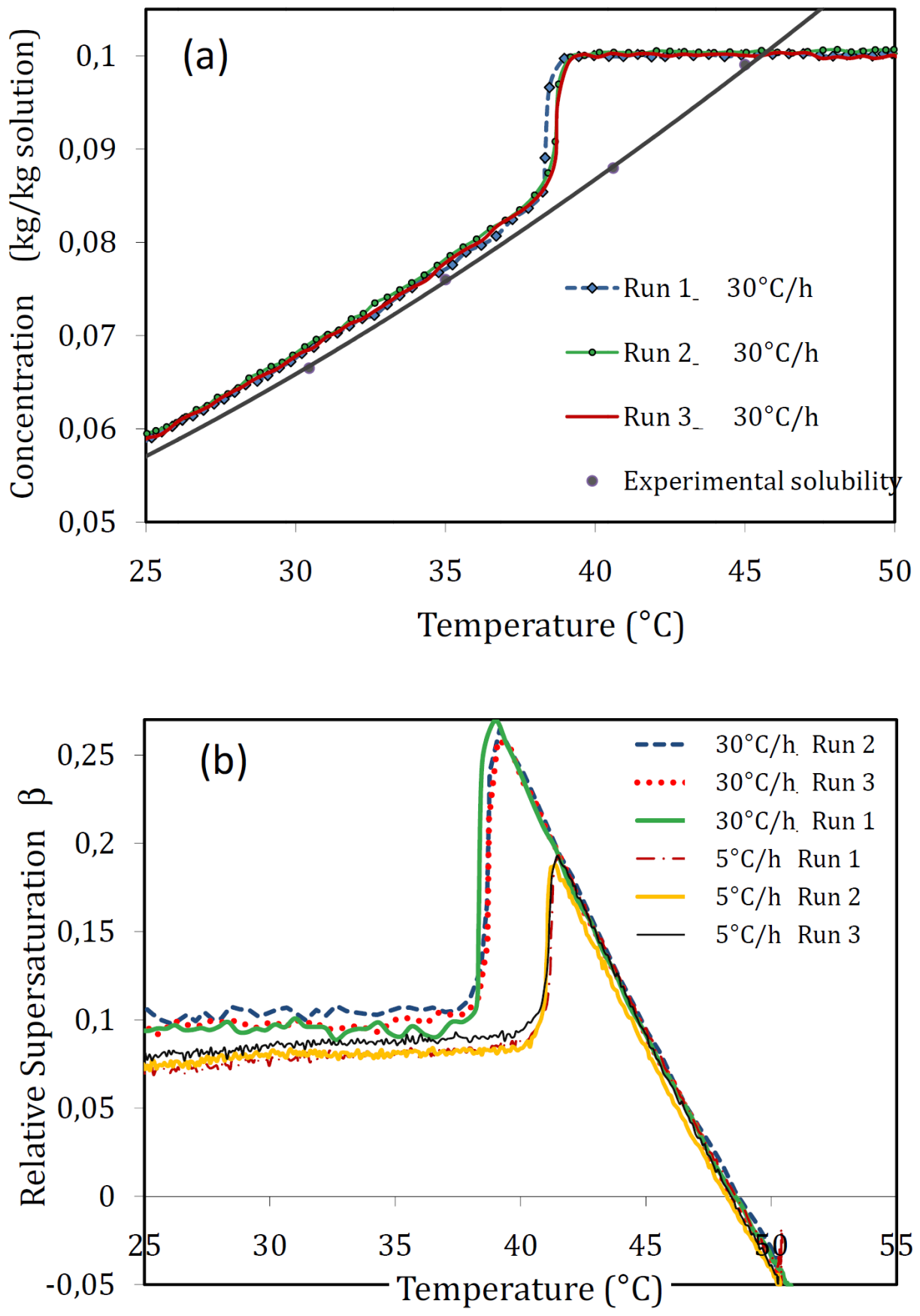

Figure 4. (a) ATR-FTIR Measurements of solute concentration during batch cooling crystallization of $\mathrm{AO}$ for a cooling rate $\mathrm{R}=-\mathrm{dT} / \mathrm{dt}=30^{\circ} \mathrm{C} / \mathrm{h}$. (b) Measured supersaturation profiles for cooling rates $\mathrm{R}=30$ and $5^{\circ} \mathrm{C} / \mathrm{h}$.

\subsection{Effect of cooling rate on MSZW}

The experimental mean values of maximum super cooling $\Delta \mathrm{T}_{\max }$ obtained by the polythermal method as a function of the cooling rate and at constant saturation temperature $\mathrm{T}_{0}=45.68^{\circ} \mathrm{C}$ are 
presented in Fig. 5. The following statistical parameters were computed: $\sigma=0.3^{\circ} \mathrm{C}$ (Standard deviation) and $\mathrm{CV}=0.63 \%$ (Variation coefficient). It is worth noting that every point in Fig.5 represents the average of 3 to 6 experimental $\Delta \mathrm{T}_{\max }$ values. As seen from Fig.5 a $\& \mathrm{~b}$, the reproducibility of the experimental data is satisfactory. The estimates at $\mathrm{R}=10{ }^{\circ} \mathrm{C} / \mathrm{h}$ and $25^{\circ} \mathrm{C} / \mathrm{h}$ exhibit a relatively large but reasonable scatter $\left( \pm 0.73^{\circ} \mathrm{C}\right.$ for $10^{\circ} \mathrm{C} / \mathrm{h}$ and $\pm 0.76^{\circ} \mathrm{C}$ for $\left.25^{\circ} \mathrm{C} / \mathrm{h}\right)$. As expected, the maximum supercooling $\Delta \mathrm{T}_{\max }$ and supersaturation $\mathrm{S}_{\max }$ increase for increasing cooling rates $\mathrm{R}$.
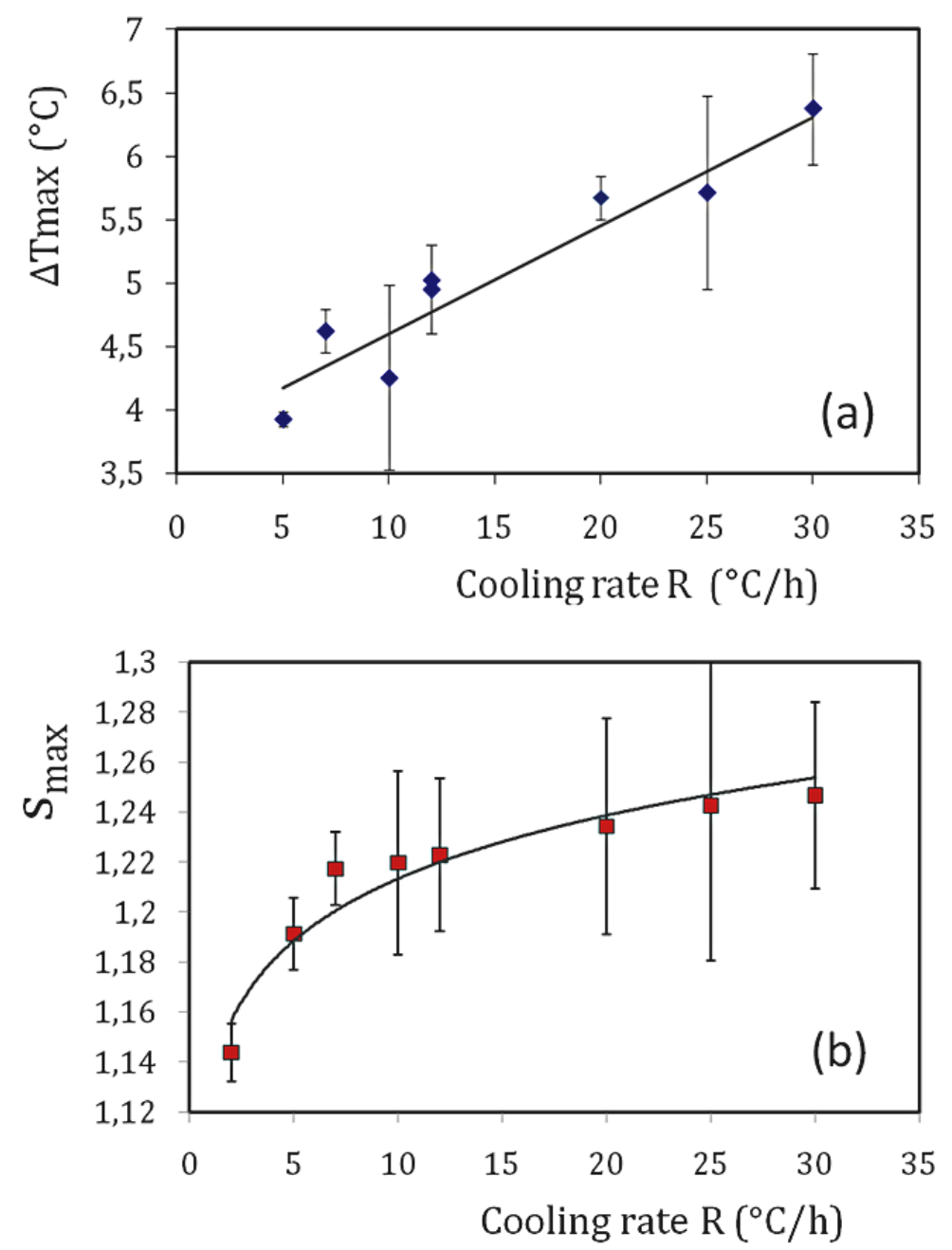

Figure 5. Variations of the maximal supercooling $\Delta \mathrm{T}_{\max }$ (a) and of the maximal supersaturation $\mathrm{S}_{\max }(\mathrm{b})$ with the cooling rate $\mathrm{R}$ (standard deviation for experimental data is shown by error bars)

\subsection{Estimated nucleation kinetics}

In order to estimate the kinetic parameters related to the different theoretical approaches mentioned above, the metastable zone width must be calculated using the experimental data. Log 
plots of the cooling rate vs. the metastable zone width for Nývlt's theory, are shown in Fig.6a, $\log$ plots of metastable zone width vs. the cooling rate for Kubota's approach, are shown in Fig.6b, and log plots of metastable zone width vs. cooling rate for Sangwal's approach, are displayed in Fig. 6c for each solute concentration.

As explained above, the slope and intercept of the trend line mapping the different calculated coordinates (i.e. according to the various methods) allow some estimation of the nucleation parameters involved. Table 1 shows the estimated nucleation parameters for the different theoretical approaches applied to the set of experimental data. Depending on the method used, the estimated parameters display a high degree of variability. As a general rule, the value of the apparent nucleation order lies between 0.98 and 8.3 for inorganic compounds $[12,28]$ and between 1.65 and 4.5 for organic compounds [29-30].

Depending on the four different approaches evaluated, the nucleation order $\mathrm{m}, \mathrm{n}$ or $1 / \beta$ were found between 3.08 and 4.76 for ammonium oxalate in water. These values are in rather good agreement with previously published data for organic materials and quite reasonable for fairly soluble compounds such as ammonium oxalate.

The nucleation kinetic parameters for the Nỳvlt's like approaches (Kubota and Sangwal), expressed in number based units, differ significantly. However, despite the range of investigated cooling rates (from $5^{\circ} \mathrm{C} / \mathrm{h}$ to $30^{\circ} \mathrm{C} / \mathrm{h}$ ) and even though the resulting maximum supersaturation range differs from that studied by Sangwal (from $\approx 10$ to $50^{\circ} \mathrm{C} / \mathrm{h}$ ); one can conclude that the results are consistent with Sangwal's estimated parameters.

Using Sangwal's 3D-CNT approach (see Table.2), the kinetic parameter A $\left(4.5410^{+25} \mathrm{~m}^{-3} \mathrm{~s}^{-1}\right)$ and the thermodynamic parameter B (0.038) obtained in this study are lower than those obtained by Sangwal [1], especially B: $\left(A=4.710^{+26} \mathrm{~m}^{-3} \mathrm{~s}^{-1}\right.$ and $\left.\mathrm{B}=0.352\right)$.

The computation of these parameters requires value of $\left(\Delta \mathrm{H}_{\mathrm{S}} / \mathrm{RgT}_{\max }\right)$, of the ratio $\mathrm{F} / \mathrm{F}_{1}$ and of individual values of both constants $\mathrm{F}_{1}$ and $\mathrm{F}$. These parameters are calculated from the experimental data and are expected to strongly depend on the saturation temperature. The ratio $\mathrm{F} /$ $F_{1}$ (equal to 0.204 in our study and to 0.176 , according to ref. [1]) and the overall parameter 
$\Delta \mathrm{H}_{\mathrm{S}} / \mathrm{RgT}_{\max }$ (equal to 8.32 in our study and to 8.74 from [1]) are quite similar in both studies. However, the individual values of $F$ and $F_{1}$, and the resulting differences of $X$ for both studies leads to an important difference within nucleation parameters estimation.

In addition, nucleation kinetic parameters provided by Nỳvlt and Kubota approaches, for the same experimental data, appear to be much lower than those obtained using Sangwal's approaches. More details about the calculation procedure concerning Sangwal's approaches and nucleation parameters estimation using experimental data obtained after this study and those obtained by Sangwal [1] are given in appendix (see Table. $3 \& 4$ ).

Fig 7 a. \& 7 b show the evolution of induction time defined in section 2.4 , as a function of the cooling rate and maximum supersaturation. As expected, the induction time decreases exponentially with increasing cooling rates and therefore increasing supersaturation levels. It is worth noting that the experimental range for the maximum supersaturation (cf. Fig.5b) investigated in the present study is included in the supersaturation/saturation temperature range investigated by Sangwal in his previous studies [1, 31].

According to the 3D nucleation theory, a plot of the logarithm of induction time against $1 /(\ln S \max )^{2} \mathrm{~T}_{\max }^{3}$, suggests that the AO system is governed by two different nucleation mechanisms occurring respectively at low cooling rates (i.e. low $\mathrm{S}_{\max }$ ) and high cooling rates (i.e. higher $S_{\max }$ ). The transition between the two possible nucleation regimes seems to take place in a zone of cooling rates roughly located between $10^{\circ} \mathrm{C} / \mathrm{h}$ and $20^{\circ} \mathrm{C} / \mathrm{h}$ : this corresponds to maximum supersaturation ratios ranging from 0.227 to 0.230 .(cf. Fig. $7 b$ \& Fig.5b) 

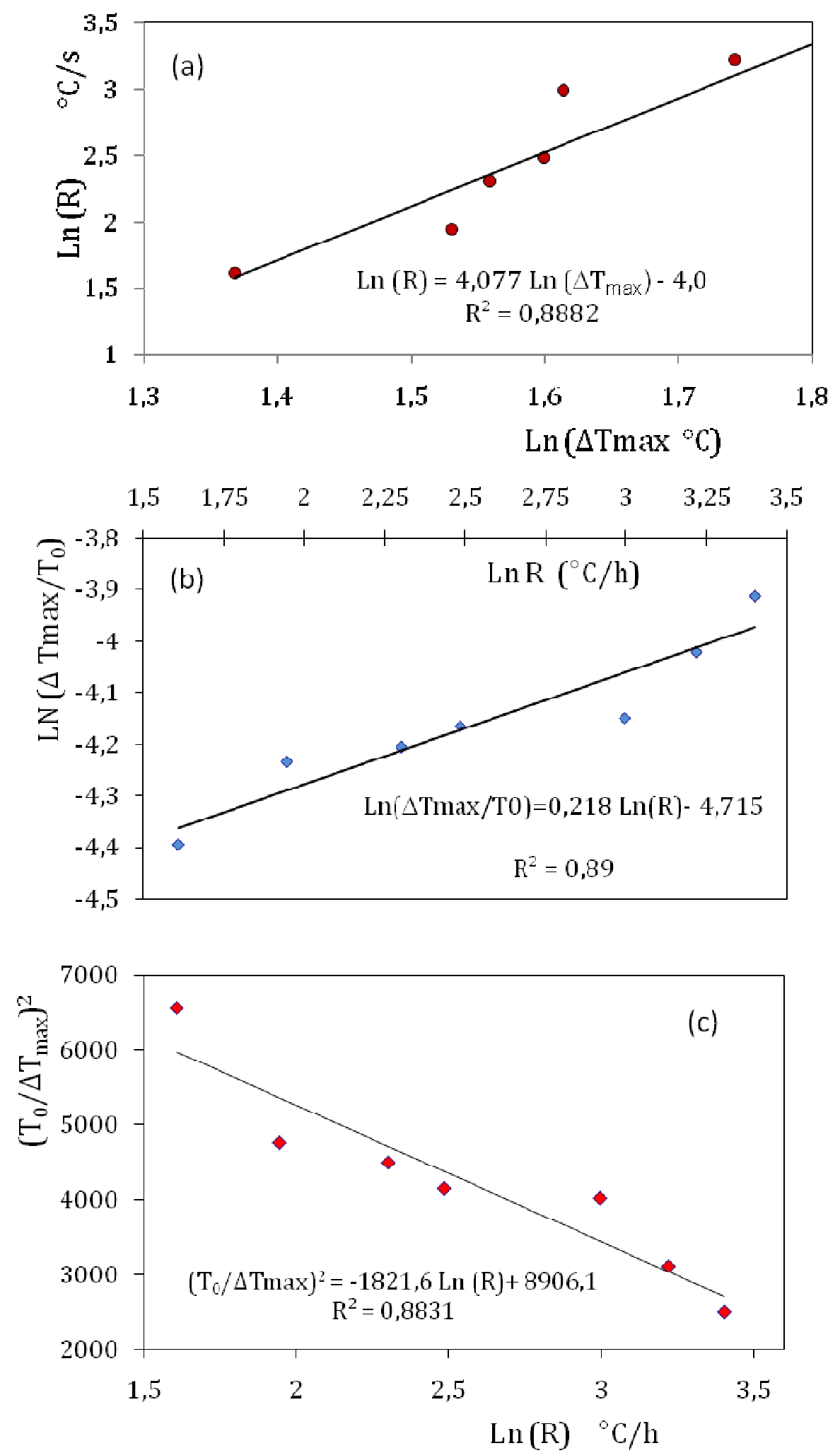

Figure 6. (a) Apparent nucleation order and nucleation constant estimated from MSZW data using Nyvlt' and Kubota's methods, (b) slopes and intercepts estimated from MSZW data using the "self-consistent" Nyvlt's method proposed by Sangwal, (c) and slopes and intercepts estimated from MSZW data using Sangwal's "3D-CNT” approach. 

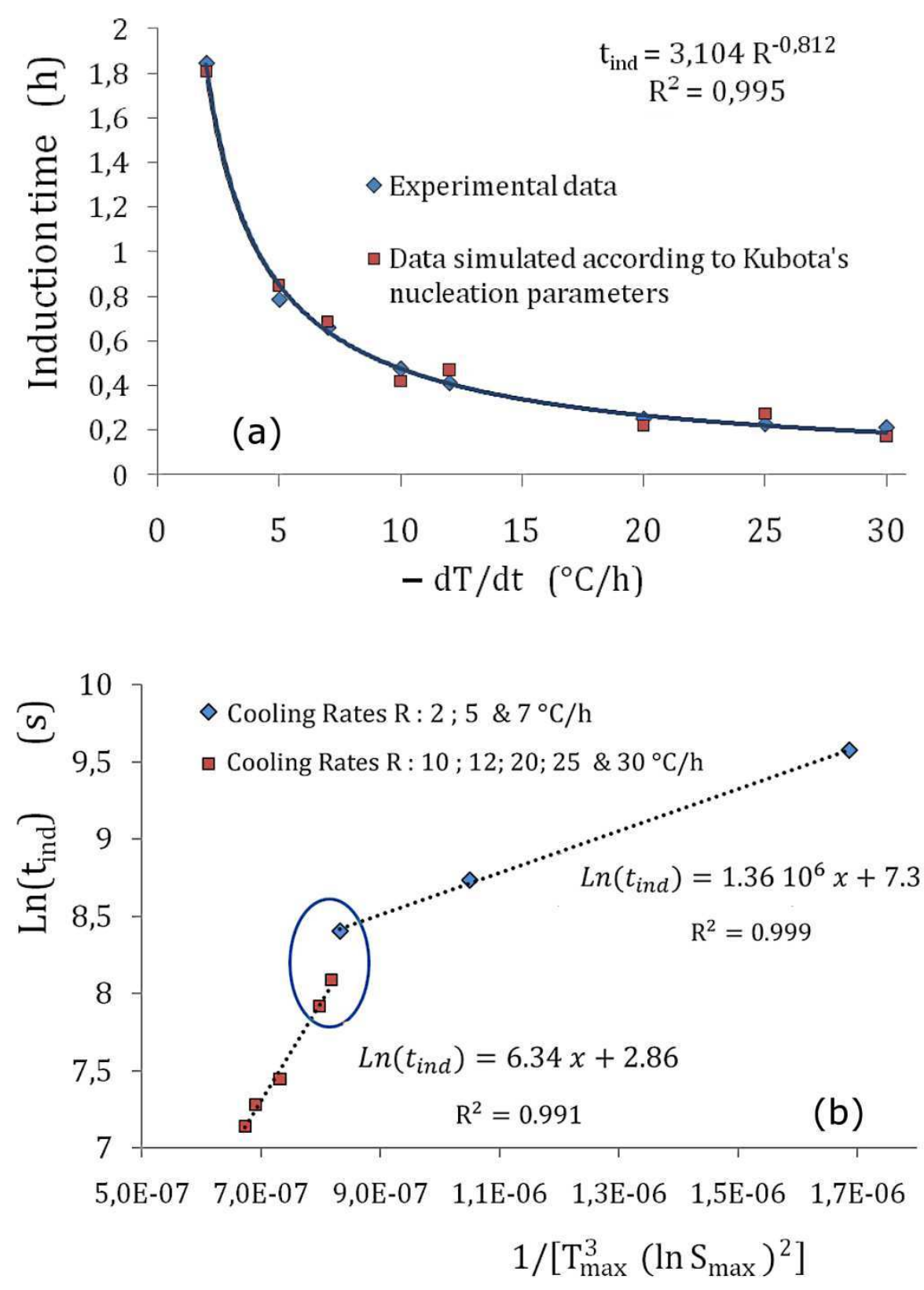

Figure 7. (a) Experimental relationship between the induction time of $\mathrm{AO}$ in water and the cooling rate, $\mathrm{R}=-\mathrm{dT} / \mathrm{dt}$ in ${ }^{\circ} \mathrm{C} / \mathrm{h}$. (b) Log plot of experimental data according to Sangwal's 3DCNT approach. Observation of two consecutive nucleation mechanisms.

From a mechanistic point of view, as pointed by Mullin [32], such a result could suggest a transition from a heterogeneous nucleation mechanism occurring at low levels of supersaturation (low cooling rates) to a homogeneous mechanism at higher supersaturation. 
From Fig. $6 \mathrm{~b}$, the ratio $\Gamma$ between the slopes is about 6 . Assuming that all variables expressed in parameter B (Eq.(7)) are unchanged for both nucleation regimes, except the interfacial energy, $\Gamma$ should reflect the difference in the interfacial energy. $\gamma$ at high cooling rates would thus be 1.82 times higher than $\gamma$ at low cooling rate $\left(0.026\right.$ and $0.014 \mathrm{~J} / \mathrm{m}^{2}$, respectively).

Using the 3D-CNT approach, Sangwal proposed $\gamma=0.015 \mathrm{j} / \mathrm{m}^{2}$. This latter result suggests a possible transition from a mononuclear nucleation mechanism to a polynuclear nucleation mechanism. Actually, according to Sangwal [33], the interfacial energy predicted by the polynuclear nucleation model would be about 1.6 times higher than that predicted by the monomolecular nucleation model which relates to small volumes or low supersaturations [33]. From the intercepts, the calculated nucleation kinetic factor for low cooling rates is 84 times higher than that obtained with high cooling rates nucleation regime.

A plot of the logarithm of induction time against the logarithm of $S_{\max }$ is expected to yield a straight line which slope is supposed to allow estimating the number of molecules in the critical nucleus [34-35]. In our case, 20 molecules for low cooling rates regime and 42 molecules for high cooling rates regime are assessed. The values of $\ln S_{\max }$ may suggest that the MSZW of AO in water investigated by the polythermal method is governed by different mechanisms depending on the cooling rate. Primary nucleation could occur for $S_{\max }>1.23$. At lower levels of supersaturation (i.e. for $S_{\max }<1.217$ ) secondary or heterogeneous nucleation could take place but the available experimental data do not allow determining which mechanism is really involved. Simulations of the cooling crystallization process of potassium sulfate [17], showed that most features related to the width of metastable zone and the induction time could be reproduced. The authors also investigated the effect of secondary nucleation on the MSZW. It was observed that secondary nucleation was favored at low cooling rates thus lowering the width of metastable zone. Indeed, many authors have published reviews of the many possible nucleation mechanisms which are likely to occur simultaneously and with varying intensity when the crystallization operating conditions change [36-37]. The simultaneous occurrence of several nucleation mechanisms was shown by Kobari et al. [17] to make the contribution of primary nucleation to 
the overall nucleation process difficult to evaluate. As far as the AO/water system is concerned, the pictures displayed in Fig.8 tend to confirm the assumption of secondary nucleation.

Induction time and metastable zone width obviously depend on the kinetics of the different processes involved in crystallization: the nucleation rate, which leads to the "birth" of crystals and the growth rate of particles which determines the time required by a given number of nucleus to produce a sufficient amount of solid to be detected. Indeed, both the initial size and mass of nuclei particles are too small to be detectable. Consequently, it is worth noting that the two regimes underlined above may also be related to growth kinetics which are not explicitly investigated by the MSZW and induction time methods addressed in the present paper.
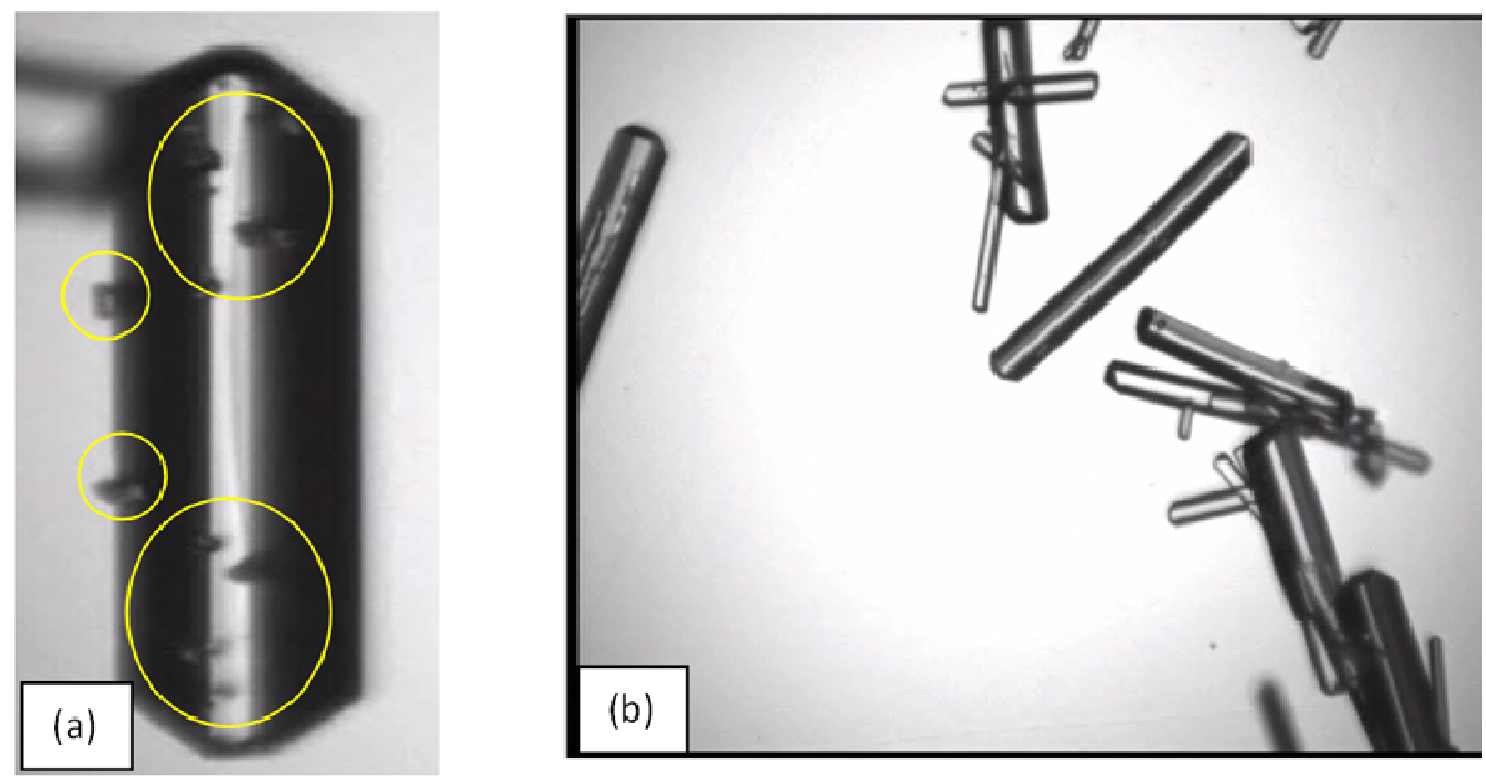

Figure 8. Pictures of AO crystals obtained in situ after unseeded cooling crystallization (in situ video acquisition). (a) Cooling rate $\mathrm{R}=5^{\circ} \mathrm{C} / \mathrm{h}$, (b) $\mathrm{R}=30^{\circ} \mathrm{C} / \mathrm{h}$.

\subsection{Assessment of the nuclei number using the obtained nucleation kinetics.}

Some relative consistency of the results provided by the different methods evaluated in this paper should be outlined, but this does not help the MSZW determination techniques to appear as rather "flimsy". Several major implicit or explicit assumptions were outlined above among which a key hypothesis should be questioned, especially when unsteady-state temperature 
variations are involved: what does "steady-state" nucleation rate really means? Actually, to our knowledge, this latter question is not rigorously addressed in the literature. From this point of view, as shown in appendix, the self-consistent Nývlt-like approach accounts for temperature changes during the crystallization process (see Eq. (17)) but this does not mean that instantaneous changes in the nucleation rates are appropriately taken into account. In fact, none of the previously applied methods rigorously take into account the intrinsic unsteady-state features of the nucleation process, especially when the highest level of supersaturation is reached during the cooling process (i.e. when the solute/solvent system reaches the limit of metastable zone). In this context, the objective of the present paper is neither to present new experimental results, nor to introduce a new version of the numerous techniques used for evaluating the MSZW or the so-called induction time. In other words, the standard MSZW or induction time methods can provide some relative and partial practical information about the nucleation process but, ideally, we suggest that one could expect new sensors to provide more reliable information on the "true" nucleation rate. As far as this is possible, the kinetics of the many possible nucleation mechanisms involved simultaneously during industrial batch crystallization operations can probably be more systematically, accurately and deeply estimated.

With this idea in view, the present results were assessed in terms of predictions of the numbers of particles predicted by the models above mentioned. The number of crystals nucleated per second during cooling crystallization performed with an initial solute concentration of $0.1 \mathrm{~kg} / \mathrm{kg}$ from $50^{\circ} \mathrm{C}$ to $20^{\circ} \mathrm{C}$ was thus computed as a function of supersaturation. For the sake of simplicity, the related PBEs were not solved here which, in turn, comes down to assume that no solid is consumed by the nucleation process. The results are quite edifying and reveal that if the maximal supersaturation is rather well predicted by the different models (i.e. the limit supersaturation where the number of particles "takes off"), the numbers of resulting nucleated particles are not even comparable. 
According to the four investigated methods (i.e. Nyvlt, Kubota, Sangwal "Nyvlt like" and Sangwal 3D-CNT) the approximate values of $\sigma_{\max }$ are : $0.05 ; 0,032 ; 0,065$ and 0.07 , respectively, but the corresponding number of particles computed for $\sigma=0.005$ (for example) are the following: $800 ; 6.510^{7} ; 4,210^{22} ; 410^{18} \# . \mathrm{m}^{-3} \mathrm{~s}^{-1}$, respectively. It therefore turns out that the "induction time" methods which essentially intend to provide data about the limit of metastable zone should not reasonably be expected to yield reliable estimates of the number of particles generated per unit time at a given level of supersaturation. Despite the very wide use of induction time methods in the literature this observation makes the many published kinetic results quite questionable. Actually it can be mathematically shown that the relationship between the induction time and the supersaturation profile exhibited by a given solute/solvent system is not one-to-one [13], but depends also on the crystal growth rate (which is quite obvious). In other words, one can demonstrate that an infinite set of nucleation/growth kinetic parameters can reproduce the same given experimental supersaturation profile measured during a batch cooling crystallization operation, even with "perfect" measurements. This is the object of ref [13] showing that the only way to cope with the indeterminacy of the "real" nucleation kinetic parameters is to take into account some relevant quantitative parameter of the CSD (e.g., the final CSD or final mean size).

\section{Conclusions:}

From the above analysis, it may be concluded that application of the different polythermal approaches developed to investigate the metastable zone width describe rather well the experimental data. However, it should be outlined that such description is rather limited.

Sangwal's approaches provide useful information about the physical processes and the kinetic parameters involved in the nucleation process. However, for the system under investigation, our results differ from Sangwal's reported data concerning the 3D-CNT approach, while a good agreement is found when the self consistent Nỳvlt's-like approach is used. 
Kubota's approach for the estimation of the MSZW provides kinetic parameters that rather well predict the experimental "polythermal" induction time measurements. Induction time measurements presented as a function of maximum supersaturation allow a better fit of the experimental results and, contrary to the other approaches, underline the existence of two nucleation regimes depending on the cooling rate and subsequent maximum supersaturation. Such dependence of the nucleation mechanism on the level of supersaturation was observed by many authors. As far as understanding and modeling the nucleation kinetics is concerned, this latter feature of the method is clearly valuable.

Due to their great simplicity and to the very rough approximations made, the methods evoked in this paper all provide relative and partial information on nucleation kinetics and, according to the used approach, the estimated parameters can be tremendously different.

The results presented here therefore show that the notion of MSZW should be handled with caution as the parameter estimates depend significantly on the experimental method carried out for their determination. In fact, it was outlined by many authors that not the onset of nucleation itself, but the appearance of a sufficient mass of crystals is indeed detected by measuring instruments, whatever their sensitivity. It is thus evident that the crystal growth rate and possible secondary nucleation phenomena play a key-role in the quantitative results, according to the employed technique (optical, calorimetric, FBRM, etc). Since distributed properties of crystals are actually involved, bringing into play population balance equations can reasonably be expected to allow significant improvements of the nucleation estimation techniques: the computation of particle size distributions coupled with crystal growth kinetics can be performed in order to allow more accurate and more robust kinetic characterization of the nucleation phenomena occurring during the course of batch crystallization processes.

\section{Acknowledgements:}

We greatly acknowledge the French Research Agency ANR (Agence Nationale de la Recherche) for the support granted to the "white project" IPAPI (Improving the Properties of Active Pharmaceutical Ingredients), ref.07-BLAN-0183 


\section{Appendix :}

\section{Self-consistent Nývlt- like equation}

From Eq.(4), using the theory of regular solutions, Sangwal relates the maximum supercooling $\Delta \mathrm{T}_{\max }$ to the corresponding maximum supersaturation. $\ln \mathrm{S}_{\max }$ is expressed as follows:

$$
\mathrm{LnS}_{\max }=\ln \left(\frac{\mathrm{C}_{\max }}{\mathrm{C}^{*}}\right)=\left(\frac{\Delta \mathrm{H}_{\mathrm{s}}}{\mathrm{R}_{\mathrm{g}}} \frac{\Delta \mathrm{T}_{\max }}{\mathrm{T}_{0} \mathrm{~T}_{\max }}\right)
$$

Assuming that the approximation $L n S_{\max } \approx \sigma_{\max } \ln S_{\max }=\sigma_{\max }$ holds, Eq. (15) can be written in the form:

$$
\sigma_{\max }=\frac{\Delta \mathrm{C}_{\max }}{\mathrm{C}^{*}}=\left(\frac{\Delta \mathrm{H}_{\mathrm{s}}}{\mathrm{R}_{\mathrm{g}}} \frac{\Delta \mathrm{T}_{\max }}{\mathrm{T}_{0} \mathrm{~T}_{\max }}\right)
$$

On the other hand, the primary nucleation rate $\mathrm{J}$ can be approximated as a function of the change in relative supersaturation with time:

$$
\mathrm{J}=\mathrm{f} \frac{\Delta \mathrm{C}_{\max }}{\mathrm{C}^{*} \Delta \mathrm{t}}=\mathrm{f} \frac{\Delta \mathrm{C}_{\max }}{\mathrm{C} * \Delta \mathrm{T}} \frac{\Delta \mathrm{T}}{\Delta \mathrm{t}}=\mathrm{f}\left(\frac{\Delta \mathrm{H}_{\mathrm{s}}}{\mathrm{R}_{\mathrm{g}} \mathrm{T}_{\max }} \frac{\mathrm{R}}{\mathrm{T}_{0}}\right)
$$

Where the constant $\mathrm{f}$ is expressed in nuclei/volume.

Substituting $l n S_{\max }$ from Eq. (8) in Eq. (7), one obtains:

$$
J=K\left(\frac{\Delta H_{s}}{R_{g}} \frac{\Delta T_{\max }}{T_{0} T_{\max }}\right)^{m}
$$

Combining Eq. (17) and Eq. (18) yields the following relationship between the dimensionless maximum temperature $\Delta \mathrm{T}_{\max } / \mathrm{T}_{\mathrm{O}}$ and the cooling rate $\mathrm{R}$ :

$$
\frac{\Delta T_{\max }}{T_{0}}=\left(\frac{f}{K T_{0}}\right)^{1 / m}\left(\frac{\Delta H_{s}}{R_{g} T_{\max }}\right)^{(1-m) / m}
$$

it follows that : $\quad \ln \left(\frac{\Delta T_{\max }}{T_{0}}\right)=\varphi^{\prime}-\beta \ln T_{0}+\beta \ln R=\varphi+\beta \ln R$

where: $\quad \varphi=\varphi^{\prime}-\beta \ln \mathrm{T}_{0}, \quad \beta=\frac{1}{\mathrm{~m}}$ and $\varphi^{\prime}=\frac{1-\mathrm{m}}{\mathrm{m}} \ln \frac{\Delta \mathrm{H}_{\mathrm{s}}}{\mathrm{R}_{\mathrm{g}} \mathrm{T}_{\max }}+\frac{1}{\mathrm{~m}} \ln \left(\frac{\mathrm{f}}{\mathrm{K}}\right)$

Eq. (20) therefore predicts linear dependence of logarithm of $\Delta \mathrm{T}_{\max } / \mathrm{T}_{0}$ on the logarithm of $\mathrm{R}$. 
Table. 3 shows the calculation procedure for nucleation parameters estimation using experimental data obtained in this study and those obtained by Sangwal in a previous study.

\section{Classical three-dimensional nucleation theory approach (3D-CNT approach)}

According to the classical nucleation theory, the nucleation rate $\mathrm{J}$ is given by Eqs.(6-7):

Combining Eqs. (6) and (15) gives:

$$
\mathrm{J}=\mathrm{A} \exp \left[-\mathrm{B}\left(\mathrm{T}_{\max } \frac{\mathrm{R}_{\mathrm{G}}}{\Delta \mathrm{Hs}}\right)^{2}\left(\frac{\mathrm{T}_{0}}{\Delta \mathrm{T}_{\max }}\right)^{2}\right]
$$

Finally, combining Eq. (17) and Eq. (21), one obtains:

$$
\exp \left[-\mathrm{B}\left(\frac{\mathrm{T}_{\max } \mathrm{R}_{\mathrm{G}}}{\Delta \mathrm{Hs}}\right)^{2}\left(\frac{\mathrm{T}_{0}}{\Delta \mathrm{T}_{\max }}\right)^{2}\right]=\mathrm{f}\left(\Delta \mathrm{H}_{\mathrm{s}} / \mathrm{R}_{\mathrm{g}} \mathrm{T}_{\max }\right)\left(\frac{\mathrm{R}}{\mathrm{AT}_{\mathrm{O}}}\right)
$$

Taking the logarithm of both sides of Eq. (22):

$$
\left(\frac{T_{0}}{\Delta T_{\max }}\right)^{2}=F_{1}\left[-\ln R+X+\ln T_{0}\right]=F-F_{1} \ln R
$$

Where,

$$
F=F_{1}\left(X+\ln T_{0}\right), \mathrm{F}_{1}=\frac{1}{\mathrm{~B}}\left(\frac{\Delta \mathrm{H}_{\mathrm{S}}}{\mathrm{R}_{\mathrm{g}} \mathrm{T}_{\max }}\right) \text { and } \mathrm{X}=\ln \left(\frac{\mathrm{A}}{\mathrm{f}} \frac{\mathrm{R}_{\mathrm{g}} \mathrm{T}_{\max }}{\Delta \mathrm{H}_{\mathrm{s}}}\right)
$$

Eq. (23) predicts that $\left(\frac{T_{0}}{\Delta T_{\max }}\right)^{2}$ decreases linearly with increasing $\ln \mathrm{R}$.

$\mathrm{F}$ and $\mathrm{X}$ are related to $\mathrm{B}$ (thermodynamic constant) and A (kinetic constant) of the 3D classical nucleation theory.

Table. 4 shows the calculation procedure for nucleation parameters estimation using experimental data obtained in this study and those obtained by Sangwal in a previous study. 


\section{References}

[1] K. Sangwal, K. Wójcik, Crystal Res. \& Technol. 44 (4) (2009), 363-372.

[2] A.J. Mahajan and D.J. Kirwan, J. Cryst. Growth 144 (3-4) (1994), 281.

[3] G. Fevotte, A. Caillet, N. Sheibat-Othman, AIChE J 53 (10) (2007), 2580-2589.

[4] A. Mersmann, Crystallization Technology Handbook (2nd ed.), Marcel Dekker Inc., New York (2001).

[5] C. Lindenberg, J. Schöll, L. Vicum, J. Brozio and M. Mazzotti, Chem. Eng. Sci. 63 (16) (2008), 4135.

[6] J. Schöll, D. Bonalumi, L. Vicum, M. Mazzotti and M. Muller, Cryst. Growth \& Des. 6 (4) (2006), 881

[7] J. Garside and A. Mersmann, Measurement of crystal growth and nucleation rates ( $2^{\text {nd }}$ ed.), Institution of Chemical Engineers: Rugby (2002).

[8] N. Kubota Journal of Crystal Growth310 (2008), 629-634.

[9] O. Söhnel1 and J. W. Mullin, J. Colloid and Interface Science 123 (1) (1988), 43-50

[10] J.W. Mullin and S.J. Jancic, Trans. IChemE 57 (3) (1979), 188-193

[11] A.R. Gerson, K.J. Roberts, J.N. Sherwood Powder Technol., 65 (1-3) (1991), p. 243-249

[12] J. Nývlt, R. Rychlý, J. Gottfried and J. Wurzelová, J. Cryst. Growth 6 (2) (1970), 151-162

[13] N. Gherras and G. Févotte, Comparison between approaches for the experimental determination of metastable zone width: a case study of the batch cooling crystallization of ammonium oxalate in water," AIChE J. (to appear), 2011.

[14] J. Nývlt, o. Söhnel, M. Matachová, and M. Broul, AIChE Journal 32 (7) (1986), 1231

[15] K-J. Kim and A. Mersmann Chem. Engi. Sci. 56 (7) (2001), 2315-2324

[16] N. S. Tavare, Batch crystallizers: A review, Chem Engng Commun, 61 (1987), p. 259-

[17] M. Kobari, N. Kubota, et I. Hirasawa, "Computer simulation of metastable zone width for unseeded potassium sulfate aqueous solution,” J. Cryst. Growth, 317, (2011), p. 64-69.

[18] N. Kubota, "A unified interpretation of metastable zone widths and induction times measured for seeded solutions," Journal of Crystal Growth, vol. 312,(2010), p. 548-554.

[19] J. Nývlt, J. Cryst. Growth 3/4 (1968), 377.

[20] K. Sangwal and E. Mielniczek-Brzóska, J. Crystal Growth 267 (3-4) (2004), 662-675

[21] A. Mersmann, and K. Bartech, Journal of Crystal Growth 183 (1998), p. 240-250.

[22] A. Mersmann. In: (1st ed.), Crystallization Technology Handbook, Marcel Dekker, New York (1994).

[23] B. Presles, J. Debayle, G. Fevotte, J.C. Pinoli, J. Electronic Imaging 19 (3) (2010) 
[24] F. Lewiner, J. P. Klein, F. Puel, G. Févotte, Chem. Eng. Sci. 56 (6) (2001), 2069-2084

[25] Févotte, G., 2002. International Journal of Pharmaceutics, 241(2), p.263-278.

[25] Timokleia Togkalidou, Mitsuko Fujiwara, Shefali Patel, Richard D. Braatz, J. Crystal Growth 231(4) (2001), 534-543

[27] O. Söhnel, and P. Novotny, (1985). Densities of Aqueous Solutions of Inorganic Substances. Physical Sciences Data 22, Elsevier, Amsterdam.

[28] Seidel, A. vol. 1 Solubilities of inorganic and metal organic compounds (1600 p).D. van Nostand Co., New York (1953).

[29] B. Menczel ，A. Apelblat; E. Korin, J. Chem.. Thermodynamics 36 (1) (2004), 41-44

[28] N. P. Rajesh, K. Meeraa, K. Srinivasanb, P. Santhana Raghavana and P. Ramasamy, Journal of Crystal Growth 213 (3-4) (2000), p.389-394[27]

[29] G. Arunmozhi, E. de M. Gomes, Crystal Research and Technol. 39 (1) (2004), 34-39

[30] S.Teychené. Control of polymorphism in pharmaceutical crystallization process : application to the crystallization of Eflucimibe drug, INP thesis, France, 2004.

[31] E.Mielniczek -Brzoska , K. Sangwal ,Crystal research \& technol. 30 (6) (1995), 807-

[32] J.W. Mullin, Crystallisation (2nd edition), Butterworths, Tokyo (1972).

[33] K. Sangwal, Additives and Crystallization Processes: From Fundamentals to Applications (2007), John Wiley \& Sons, Ltd.

[34] D. Verdoes, D. Kashchiev, G. M. van Rosmalen, J.Cryst. Growth 118 (3-4), (1992), 401413

[35] D. Kashchiev, D. Verdoes, G. M. van Rosmalen, J.Cryst. Growth, 110 (3, 2), (1991), 373380.

[36] A. Mersmann, "Design of Crystallizers," Chem. Eng.\& Processing, vol. 23, Juin. 1988, p. 213-228.

[37] A.F. Blandin, D. Mangin, V. Nallet, J.P. Klein, J.M. Bossoutrot, Chem. Eng. J. 81 (2001) 91-100. 


\section{Figures Captions}

Figure 1: Experimental set up: temperature controlled and well-mixed lab-scale batch crystallizer equipped with ATR-FTIR and in situ image acquisition probes.

Figure 2: 2D images obtained using the in situ imaging probe, "EZ-Probe": acquisition of the very first observable crystals in the crystallizer after the onset of nucleation.

Figure 3: ATR-FTIR Measurements of the solubility curve of amonium oxalate using methods 1 and 2, and comparison with literature solubility data (Seidel [28] and Menzel et al., [29]).

Figure 4. (a) ATR-FTIR Measurements of solute concentration during batch cooling crystallization of $\mathrm{AO}$ for the cooling rate $\mathrm{R}=-\mathrm{dT} / \mathrm{dt}=30^{\circ} \mathrm{C} / \mathrm{h}$. (b) Measured supersaturation profiles for cooling rates $\mathrm{R}=30$ and $5^{\circ} \mathrm{C} / \mathrm{h}$.

Figure 5. Variations of the maximal supercooling $\Delta \mathrm{T}_{\max }$ (a) and of the maximal supersaturation $\mathrm{S}_{\max }(\mathrm{b})$ with the cooling rate $\mathrm{R}$ (The standard deviation is shown by error bars)

Figure 6. (a) Apparent nucleation order and nucleation constant estimated from MSZW date using Nyvlt' and Kubota's methods, (b) slopes and intercepts estimated from MSZW data using the "self-consistent" Nyvlt's method proposed by Sangwal, (c) and slopes and intercepts estimated from MSZW data using Sangwal's "3D-CNT" approach.

Figure 7. (a) Experimental relationship between the induction time of $\mathrm{AO}$ crystallization in water and the cooling rate, $\mathrm{R}=-\mathrm{dT} / \mathrm{dt}$ in ${ }^{\circ} \mathrm{C} / \mathrm{h}$. (b) $\log$ plot of experimental data according to Sangwal's 3D-CNT approach. Two consecutive nucleation mechanisms can be observed.

Figure 8. Pictures of AO crystals obtained in situ after unseeded cooling crystallization (in situ video acquisition). (a) Cooling rate $\mathrm{R}=-5^{\circ} \mathrm{C} / \mathrm{h}$, (b) $\mathrm{R}=-30^{\circ} \mathrm{C} / \mathrm{h}$. 


\section{Tables Captions}

Table 1. Results from kinetics parameter estimation using different Nỳvlt - like nucleation theories 1. Calculations based on a minimum of 3 concentrations with a $95 \%$ confidence level (note that $\mathrm{m}=1 / \beta$ )

Table 2. Results from kinetics parameter estimation using 3D-CNT nucleation theory at a $95 \%$ confidence level. Calculations based on a minimum of 3 concentrations.

Table.3 Results from kinetics parameter estimation using self consistent Nỳvlt-like nucleation theory at a $95 \%$ confidence level. Calculations based on a minimum of 3 concentrations.

Table.4 Results from kinetics parameter estimation using 3D-CNT nucleation theory at a $95 \%$ confidence level. 